\title{
Anabolic-Androgenic Steroid (AAS) Induced Bowel Ulcers Mimicking Inflammatory Bowel Disease in a Young Man
}

\author{
Devamsh Arora ${ }^{1}$, Priyanka Yadav², Vidiyala Harika ${ }^{3}$, Akshay Dafal $^{4}$, Sourya Acharya ${ }^{5}$, Samarth Shukla ${ }^{6}$
}

${ }^{1}$ Datta Meghe Institute of Medical Sciences (Deemed to be University), Sawangi (Meghe), Wardha, Maharashtra, India

${ }^{2}$ Datta Meghe Institute of Medical Sciences (Deemed to be University), Sawangi (Meghe), Wardha, Maharashtra, India.

${ }^{3}$ Department of Medicine, Datta Meghe Institute of Medical Sciences (Deemed to be University), Sawangi (Meghe),

Wardha, Maharashtra, India. ${ }^{4}$ Department of Medicine, Datta Meghe Institute of Medical Sciences (Deemed to be University), Sawangi (Meghe), Wardha, Maharashtra, India. ${ }^{5}$ Department of Medicine, Datta Meghe Institute of Medical Sciences (Deemed to be University), Sawangi (Meghe), Wardha, Maharashtra, India. ${ }^{6}$ Department of Pathology, Datta Meghe Institute of Medical Sciences (Deemed to be University), Sawangi (Meghe), Wardha, Maharashtra, India.

\section{INTRODUCTION}

Anabolic - androgenic steroids (AAS) are synthetic, or human-made variations of the male sex hormone testosterone. The proper term for these compounds is anabolicandrogenic steroids. "Anabolic" refers to muscle building, and "androgenic" refers to increased male sex characteristics. Some of the most common anabolic steroids taken today are anadrol, oxandrin, dianabol, winstrol, deca-durabolin, and equipoise. These steroids are used for medical conditions, but people also use them illegally to boost muscle mass, performance, and endurance and to shorten recovery time between workouts causing cardiac diseases, GI ulcers, hormonal disturbances, depression, etc. We present a case of a young male who was abusing AAS as performance enhancer, presented to us with chronic abdominal pain and later on colonoscopy. He was diagnosed to have multiple colonic ulcers.

Testosterone first synthesized in Germany in 1935 was initially used for the treatment of depression.[2,3] Misuse of anabolic steroids was started in 1954 Olympics, when Russian weightlifters were given testosterone which is known to increase the muscle mass. ${ }^{[4]}$ More benefit is seen for strength-dependent sports [weightlifting, shot-put throwing, football] than for sports that require speed, agility, flexibility, and/or endurance.[5] In the 1980s, anabolic steroid use began to extend into the general population and the vast majority of people who misuse anabolic steroids are male non-athlete weightlifters in their 20 s or 30 in order to achieve their ideal body.[6-8] Anabolic steroids have been used in recovery from catabolic states, as it maintains adequate nitrogen balance and therefore helps in tissue healing and the maintenance of muscle mass. ${ }^{[9]}$ The abuse of these drugs has been linked to many clinical manifestations like cardiac arrest, ischemic stroke, $[10,11]$ hypertension ${ }^{[12]}$ and infections like HIV and hepatitis B and C.[13] The abuse of these drugs also cause oligospermia.[14-16] gynaecomastia and male pattern baldness.[17,18] in males while in females it causes excessive body hair, coarse skin ${ }^{[19]}$ and decreased breast size.[20] Although many of the undesirable effects of anabolic steroid abuse have been reported, little is known about its involvement in the causation of colonic ulcers and the same has not been thoroughly discussed before.

\author{
Corresponding Author: \\ Dr. Sourya Acharya, \\ Professor, \\ Department of Medicine, \\ DMIMS University, Sawangi (Meghe), \\ Wardha-442001, Maharashtra, India. \\ E-mail: souryaacharya74@gmail.com
}

DOI: $10.14260 /$ jemds/2019/826

Financial or Other Competing Interests: None.

How to Cite This Article:

Arora D, Yadav P, Harika V, et al. Anabolicandrogenic steroid (AAS) induced bowel ulcers mimicking inflammatory bowel disease in a young man. J. Evolution Med. Dent. Sci. 2019;8(50):3816-3818, DOI: 10.14260/jemds/2019/826

Submission 06-09-2019,

Peer Review 26-11-2019,

Acceptance 03-12-2019,

Published 16-12-2019. 


\section{PRESENTATION OF CASE}

A 24-year-old male presented with complaints of abdominal pain since 4 weeks which was diffuse (all over the abdomen) and is of dull aching type which is not relieved on consumption of food. Patient also had h/o loose stools since 3 weeks, mucoid in consistency which were associated with pain abdomen and tenesmus. Patient had fever since 2 weeks which was associated with chills and rigors.
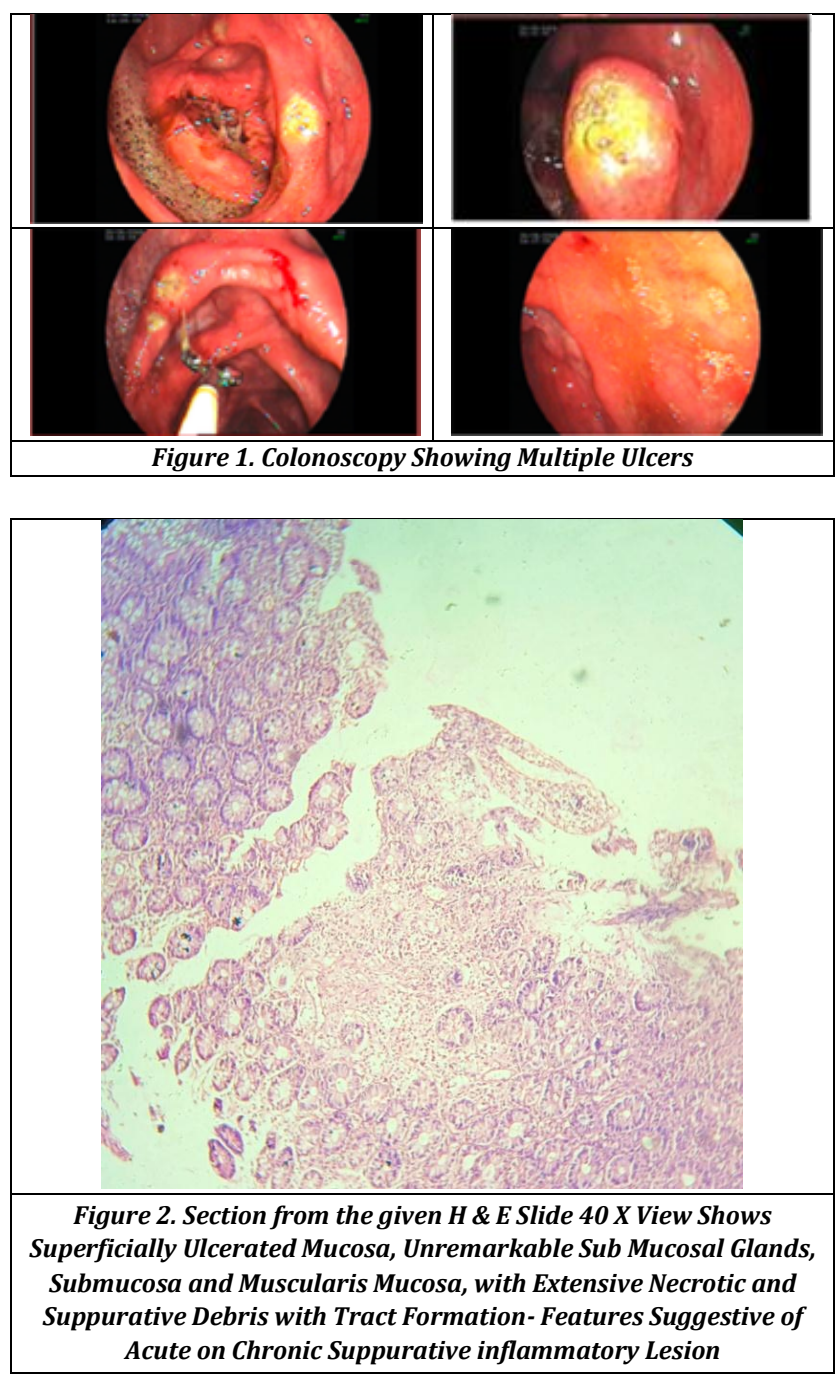

The patient had no history of alcohol intake. He exercised in a local gymnasium and was basically a body builder. On asking leading questions he agreed of taking anabolic steroids for performance enhancement. He was taking injection Testosterone enanthate $200 \mathrm{mg} I \mathrm{M}$ every month for 7 months and tablet Oxandrolone $20 \mathrm{mg}$ orally 5 times a week since 6 months. There was no history travel to any other region. There was no history of hematemesis, melena, hematochezia, heart burn, chest pain, jaundice in the past. The patient took 2 separate courses of Tablet. Ciprofloxacin and tablet. Tinidazole each for 7 days by different private practitioners without any relief. His general physical examination was normal. CVS and RS examination did not reveal any abnormality. Per abdomen examination revealed diffuse abdominal tenderness on light palpation. There was no organomegaly. Bowel sounds were normal.

\section{PATHOLOGICAL DISCUSSION}

TLC 11,900/mm 3 with predominant leukocytosis. Hb- 9 gm\%, KFT, was normal. LFT: Serum bilirubin $1.8 \mathrm{mg} \%$, ALT - 78 IU/L, AST - 64 IU/L, Serum alkaline phosphatase $180 \mathrm{IU} / \mathrm{L}$. Serum Amylase and lipase were within normal. Fasting blood sugar and lipid profile was normal. Ig M Antibodies against the yeast Saccharomyces cerevisiae [ASCA] and against neutrophils [P- ANCA] were negative. USG abdomen was normal. A colonoscopy was performed which revealed multiple discrete ulcers in the descending colon. [Figure-1] Histopathologic examination of the biopsy revealed features of non granulomatous inflammation. [Figure- 2]

\section{DISCUSSION}

Anabolic- androgenic steroids [AAS] are known to cause multi organ damage secondary to supra optimal dosage taken by the athletes. They increase the risk of atherogenesis.[21,22] Within the gastro intestinal system main side effects of Anabolic steroids are increased levels AST, ALT and LDH[23] which tend to peak in the $2^{\text {nd }}$ to $3^{\text {rd }}$ week of drug administration and are known to return to normal levels after discontinuation. [23] Steroids induce a wide range of hepatic disorders ranging from impaired excretion, cellular hepatocyte changes, cholestasis, peliosis hepatis, and hepatocellular hyperplasia to carcinomas majority being benign adenomas have been reported.[23]

Effect of exogenous steroids is expressed on the hypothalamic pituitary gonadal axis through negative feedback mechanism.[23] Increased consumption of testosterone leads to rise in estradiol causing heightened voice and gynaecomastia which may be painful.[24] AAS caused mild elevation of serum creatinine.[25] Weight lifters consuming anabolic steroids along with creatinine supplements may increase renal damage.

AAS also increase potassium due to retention of sodium and metabolic alkalosis along with hypokalaemia due to excretion of $\mathrm{H}+{ }^{[6]}$ These are the known side effects caused by the anabolic steroids. Ulcers in the large intestine due to AAS abuse has not been reported till date. This is a rare case where the patient presented with intestinal ulcers secondary to AAS abuse for increasing muscle strength. The histopathologic features ruled out characteristic features of inflammatory bowel disease [Ulcerative colitis and Crohn's disease] and the serologic markers were absent in our case.

\section{REFERENCES}

[1] Kuhn CM. Anabolic steroids. Recent Prog Horm Res 2002;57:411-34.

[2] McHenry J, Carrier N, Hull E, et al. Sex differences in anxiety and depression: role of testosterone. Frontiers in Neuroendocrinology 2014;35(1):42-57.

[3] Freeman ER. Bloom DA, McGuire EJ. A brief history of testosterone. The Journal of Urology 2001;165(2):371-3. 
[4] Wade N. Anabolic steroids: doctors denounce them, but athletes aren't listening. Science 1972;176(4042):1399403.

[5] American Academy of Pediatrics. Adolescents and anabolic steroids: a subject review. American Academy of Pediatrics. Committee on Sports Medicine and Fitness. Pediatrics 1997;99(6):904-8.

[6] Buckley WE, Yesalis CE 3rd, Friedl KE, et al. Estimated prevalence of anabolic steroid use among male high school seniors. JAMA 1988;260(23):3441-5.

[7] Kanayama G, Boynes M, Hudson JI, et al. Anabolic steroid abuse among teenage girls: an illusory problem? Drug Alcohol Depend 2007;88(2-3):156-62.

[8] Kanayama G, Pope HG Jr. History and epidemiology of anabolic androgens in athletes and non-athletes. Mol Cell Endocrinal 2018;464:4-13.

[9] El Scheich T, Weber AA, Klee D, et al. Adolescent ischemic stroke associated with anabolic steroid and cannabis abuse. J Pediatr Endocrinol Metab JPEM 2013;26(12):161-5.

[10] Santamarina RD, Besocke AG, Romano LM, et al. Ischemic stroke related to anabolic abuse. Clin Neuropharmacol 2008;31(2):80-5.

[11] Urhausen A, Albers T, Kindermann W. Are the cardiac effects of anabolic steroid abuse in strength athletes reversible? Heart Br Card Soc 2004;90(5):496-501.

[12] Ip EJ, Yadao MA, Shah BM, et al. Infectious disease, injection practices and risky sexual behavior among anabolic steroid users. AIDS Care 2016;28(3):294-9.

[13] Bonetti A, Tirelli F, Catapano A, et al. Side effects of anabolic androgenic steroids abuse. Int J Sports Med 2008;29(8):679-87.

[14] Liu PY, Swerdloff RS, Christenson PD, et al. Rate, extent and modifiers of spermatogenic recovery after hormonal male contraception: an integrated analysis. Lancet 2006;367(9520):1412-20.
[15] Torres-Calleja J, González-Unzaga M, DeCelis-Carrillo R, et al. Effect of androgenic anabolic steroids on sperm quality and serum hormone levels in adult male bodybuilders. Life Sci 2001;68(15):1769-74.

[16] Calzada L, Torres-Calleja J, Martinez JM, et al. Measurement of androgen and estrogen receptors in breast tissue from subjects with anabolic steroiddependent gynecomastia. Life Sci 2001;69(13):1465-9.

[17] Orlandi MA, Venegoni E, Pagani C. Gynecomastia in two young men with histories of prolonged use of anabolic androgenic steroids. J Ultrasound 2010;13(2):46-8.

[18] Scott MJ 3rd, Scott AM. Effects of anabolic-androgenic steroids on the pilosebaceous unit. Cutis 1992;50(2):1136.

[19] Baker J. A report on alterations to the speaking and singing voices of four women following hormonal therapy with virilizing agents. J Voice 1999;13(4):496-507.

[20] National Institute on Drug Abuse Research Report Steroid Abuse and Addiction. National Institutes of Health Publication No. 00-3721. Bethesda: National Institutes of Health, 2000.

[21] Hartgens F, Kuipers H. Effects of androgenic-anabolic steroids in athletes. Sports Med 2004;34(8):513-54.

[22] Friedl KE. Effects of anabolic steroids on physical health. In: Yesalis CE, edr. Anabolic steroids in sport and exercise. Champaign: Human Kinetics 1993: p. 107-50.

[23] Reents S. Androgenic-anabolic steroids. In: Sport and exercise pharmacology. Champaign: Human Kinetics 2000: p. 161-81.

[24] Juhn M. Popular sports supplements and ergogenic aids. Sports Med 2003;33(12):921-39.

[25] Maravelias C, Dona A, Stefanidou M, et al. Adverse effects of anabolic steroids in athletes: a constant threat. Toxicol Lett 2005;158(3):167-75. 